\title{
Gyrate Atrophy
}

National Cancer Institute

\section{Source}

National Cancer Institute. Gyrate Atrophy. NCI Thesaurus. Code C84744.

A rare autosomal recessive inherited disorder caused by mutations in the OAT gene. It is characterized by progressive atrophy of the retina and choroid, leading to loss of vision and blindness. 